Military Technical College Kobry El-Kobba

Cairo, Egypt



12-th International Conference on Aerospace Sciences \& Aviation Technology

\title{
VIBRATION ATTENUATION IN A PERIODIC ROTATING TIMOSHENKO BEAM
}

\author{
MAGED ALAA EL-DIN and MOHAMMAD TAWFIK
}

\begin{abstract}
In this study we investigate the effect of abrupt geometric discontinuities on the vibration of a Timoshenko rotating beam. The beam model is created using finite element code developed on MATLAB. Stop and pass bands are identified using periodic analysis for single cell. The results are verified using published data. Numerical results indicate the effectiveness of such structure configuration on vibration attenuation.
\end{abstract}

\section{KEY WORD:}

Passive Damping, Periodic Structures, Rotating Structures and Thick Beams

\footnotetext{
* Graduate Student, Vibration and Acoustics Control Centre, Noon for Researches and Developments, www.noonrd.org, Cairo, Egypt.

** Assistant Professor, Modelling \& Simulation in Mechanics Department, Faculty of Engineering \& Material Science, German University in Cairo, New Cairo City, Egypt.
} 


\section{INTRODUCTION}

The term "Periodic Structure" is used to describe structures that consist of a set of identical parts, cells, connected together. Periodic Structures have drawn the attention of researchers since the mid-sixties [1]-[9] because of their high ability to attenuate vibrations. Meanwhile, special attention is given to rotating beams [10]-[23] as rotating beams have wide range of engineering applications. Special attention is given to short beams where rotary inertia is taken into consideration [12], [14], [16], [20], [21] and [23] . In this paper, we will present an attempt to demonstrate the ability of geometrical periodicity of a rotating Timoshenko beam to attenuate vibrations.

\section{Periodic Rotating Timoshenko Beam}

\subsection{Displacement field}

Figure 1 shows the configuration of a periodic rotating Timoshenko cantilever beam. The beam of length $(L)$ is connected to a rigid hub of radius (a) and rotates about the hub axis with angular velocity $(\Omega)$. The beam itself consists of geometrically identical cells. Each cell consists of two elements as shown in Figure 2. Each element is three nodded elements with four degrees of freedom per node.

The total deflection of the element as shown in Figure 3 at location $(x)$ in z-direction can be expressed by:

$$
w(x)=w_{b}(x)+w_{s}(x)
$$

Where the subscripts $b$ and $s$ denotes the bending and shear deformations in $x z$ plane respectively. Both deformations are assumed to be fifth order polynomials. They are similar in nature but different in nodal displacements. The elements degrees of freedom can be expressed by:

$$
\begin{aligned}
& w_{i}(x)=\left\lfloor N_{1}(x) \quad N_{2}(x) \quad N_{3}(x) \quad N_{4}(x) \quad N_{5}(x)\right\rfloor \times\left\lfloor\begin{array}{llllll}
w_{i 1} & w_{i 1}^{\prime} & w_{i 2} & w_{i 2}^{\prime} & w_{i 3} & w_{i 3}^{\prime}
\end{array}\right]^{T} \\
& \text { Or: } \\
& w_{i}(x)=\lfloor N(x)\rfloor\left\{w_{i}^{e}\right\}
\end{aligned}
$$

Where $N(x)$ is the shape function and $w_{i}$ denotes either $w_{b}$ or $w_{s}$.

\subsection{Total system energy}

\subsubsection{Strain energy}

The system strain energy due to bending deformation and rotary inertia can be expressed as follows:

$$
U=\frac{1}{2} \int_{0}^{l}\left\{E I_{y y}\left(\frac{\partial^{2} w_{b}}{\partial x^{2}}\right)^{2}+G A K_{s}\left(\frac{\partial^{2} w_{s}}{\partial x^{2}}\right)^{2}\right\} d x+\frac{1}{2} \int_{0}^{l} f_{c}(x)\left(\frac{\partial w_{b}}{\partial x}+\frac{\partial w_{s}}{\partial x}\right)^{2} d x
$$


Where $E$ and $G$ are Young's modulus elasticity and modulus of rigidity, $K_{s}$ is the shear factor, $I_{y y}$ and $A$ are the moment of inertia of cross-section and its area. $f_{c}(x)$ is the centrifugal force due to rotation. The centrifugal force will be discussed in details later in this section.

\subsubsection{Kinetic energy}

The element kinetic energy $(T)$ is given by:

$$
T=\frac{1}{2} \int_{0}^{l} \rho I_{y y}\left(\frac{\partial^{2} w_{b}}{\partial x \partial t}\right)^{2} d x+\frac{1}{2} \int_{0}^{l} \rho A\left(\frac{\partial w_{b}}{\partial t}+\frac{\partial w_{s}}{\partial t}\right)^{2} d x
$$

Where $\rho$ is the mass density.

\subsubsection{External Work}

The external work due to externally applied force $(F)$ is given by:

$$
W=\int_{0}^{l} w F d x
$$

\subsection{Hamilton's Principle}

According to Hamilton's principle, the first variation of the system total energy equals to zero.

$$
\delta \Pi=\int_{t_{1}}^{t_{2}}(U-T-W) d t=0
$$

\subsubsection{Stiffness matrix}

The stiffness matrix can be derived by taking the first variation for the first integral of strain energy given by equation (3):

$$
[K]=\left[\begin{array}{cc}
{[K B]} & {[0]} \\
{[0]} & {[K S]}
\end{array}\right], \quad[K B]=\int_{0}^{l} E I_{y y}\left\{N_{x x}\right\}\left\lfloor N_{x x}\right\rfloor d x, \quad[K S]=\int_{0}^{l} G A K_{s}\left\{N_{x x}\right\}\left\lfloor N_{x x}\right\rfloor d x
$$

where the subscript $x$ denotes differentiation once with respect to $x$.

\subsubsection{Rotation-induced stiffness matrix}

The rotation-induced stiffness is the added stiffness due to centrifugal force. It can be derived by taking the first variation of the second integral of strain energy in equation (3):

$$
[S]=\left[\int_{0}^{l} f_{c}(x)\left\{N_{x}\right\}\left\lfloor N_{x}\right\rfloor d x\right]
$$




\subsubsection{Mass matrix}

The Mass matrix can be evaluated by taking the first variation of the kinetic energy, given by equation (4), and integrating by parts once:

$$
[M]=\left[\begin{array}{cc}
{[M S]+[M B]} & {[M B]} \\
{[M B]} & {[M B]}
\end{array}\right], \quad[M S]=\int_{0}^{l} \rho I_{y y}\left\{N_{x}\right\}\left[N_{x}\right\rfloor d x,[M B]=\int_{0}^{l} \rho A\{N\}\lfloor N\rfloor d x
$$

\subsubsection{Force vector}

The vector of externally applied force can be expressed by:

$$
\{F\}=\int_{0}^{l} F\{N\} d x
$$

\subsubsection{Element matrix equation}

Finally the element matrix equations can be expressed by:

$$
\left[\begin{array}{cc}
{[M S]+[M B]} & {[M B]} \\
{[M B]} & {[M B]}
\end{array}\right]\left\{\begin{array}{l}
\ddot{w}_{b} \\
\ddot{w}_{s}
\end{array}\right\}+\left(\left[\begin{array}{cc}
{[K B]} & {[0]} \\
{[0]} & {[K S]}
\end{array}\right]+\Omega^{2}\left[\begin{array}{cc}
{[s]} & {[s]} \\
{[s]} & {[s]}
\end{array}\right]\right)\left\{\begin{array}{l}
w_{b} \\
w_{s}
\end{array}\right\}=\{F\}
$$

\subsection{Centrifugal Force}

The centrifugal force induced by rotation at station $(x)$ within the $i^{\text {th }}$ element, measured from its left end can be expressed as follows:

$$
f_{c}(x)=\int_{a+x_{i}+x}^{a+L} \rho A \zeta d \zeta
$$

Where $(a)$ is the hub radius, $\left(x_{i}\right)$ is the distance from the beam root to the left end of the element. $(\zeta)$ is a local coordinate parallel to $x$-coordinate and is measured from the general station $(x)$ as shown in Figure 1.

Since the beam is not uniform, the integration in equation (12) should be rewritten as:

$$
f_{c}(x)=f_{0}(x)+f_{1}
$$

Where:

$$
f_{0}(x)=-\rho A_{i}\left(\left(a+x_{i}\right) x+0.5 x^{2}\right), \quad f_{1}=\rho A_{i}\left(\left(a+x_{i}\right) L_{i}+\frac{L_{i}^{2}}{2}\right)+\sum_{j=i+1}^{n} \rho A_{j}\left(\left(a+x_{j}\right)_{j}+\frac{L_{j}^{2}}{2}\right)
$$

Where $\rho A_{j}, x_{j}$ and $L_{j}$ is the mass per unit length of the $j^{\text {th }}$ element, distance from root to its left end and its length respectively. 


\subsection{Periodic Analysis}

When a wave faces abrupt change in geometry and/or material properties, part of it reflected. This reflection is destructive in some frequency bands called stop bands. In order to locate these stop bands, transfer matrix analysis is used to formulate an input/output relation between forces and displacements at left (node 1) and right (node 5) ends of the cell. See Figure 2.

$$
\left\lfloor K_{\text {dynamic }} \mid\{w\}_{\text {cell }}=\{F\}_{\text {cell }}, \quad\left[K_{\text {dynamic }}\right]=\left(K+\Omega^{2} S-\omega^{2} M\right)\right.
$$

By condensing the internal nodes, the above relation can be rewritten as:

$$
\left[\begin{array}{ll}
K_{11} & K_{12} \\
K_{21} & K_{22}
\end{array}\right]\left\{\begin{array}{l}
w_{1} \\
w_{5}
\end{array}\right\}=\left\{\begin{array}{l}
F_{1} \\
F_{5}
\end{array}\right\}
$$

where $w_{1}, F_{1}, W_{5}$ and $F_{5}$ are the displacements and forces at nodes 1 and 5 respectively. Rewriting the above equation in form of input/output relation:

$$
\left[\begin{array}{ll}
T_{11} & T_{12} \\
T_{21} & T_{22}
\end{array}\right]\left\{\begin{array}{l}
w_{1} \\
F_{1}
\end{array}\right\}=\left\{\begin{array}{l}
w_{5} \\
F_{5}
\end{array}\right\}
$$

Assume:

$$
\left\{\begin{array}{c}
w_{5} \\
F_{5}
\end{array}\right\}=e^{\mu}\left\{\begin{array}{c}
w_{1} \\
-F_{1}
\end{array}\right\}
$$

Substituting equation (18) into (17):

$$
[T]\left\{\begin{array}{l}
w_{1} \\
F_{1}
\end{array}\right\}=e^{\mu}\left\{\begin{array}{l}
w_{1} \\
F_{1}
\end{array}\right\},[T]=\left[\begin{array}{cc}
T_{11} & T_{12} \\
-T_{21} & -T_{22}
\end{array}\right]
$$

The above eigenvalue problem can be solved for propagation factor $\mu$, which is, generally, a complex number its real part represents the boundaries of the pass/stop bands, and the imaginary part gives the attenuation value. Since the transfer matrix $[T]$ varies from one cell to another, the location of stop bands will vary to. Thus average will be taken for all cells.

\section{NUMERICAL RESULTS}

The finite element model described above has been developed on MATLAB 7.0. Herein after, some numerical results are listed for comparison purposes. However, no test data are published for rotating periodic Timoshenko beam. Thus, comparison will be accomplished on two steps. The first, comparing the natural frequencies 


\subsection{Uniform Rotating Timoshenko Beam}

Stafford and Giurgiutiu [10] derived semi-analytical methods to evaluate natural frequencies of rotating Timoshenko beam. Table 1 contains comparison between the current finite element model and reference [10]. These non-dimensional natural frequencies are calculated for beam with characteristics stated in Table 2. From Table 1, the finite element model showed good agreement.

Table 1: Non-dimensional natural frequencies of uniform rotating Timoshenko beam

\begin{tabular}{|c|c|c|}
\hline Mode & Exact Ref. [10] & Current Model \\
\hline 1 & 6.8509 & 6.9301 \\
\hline 2 & 19.6787 & 19.839 \\
\hline 3 & 38.5758 & 38.679 \\
\hline 4 & 56.295 & 55.229 \\
\hline
\end{tabular}

Table 2: Characteristics of uniform rotating Timoshenko beam

\begin{tabular}{|c|c|c|c|c|c|c|}
\hline$L$ & $E l$ & $\rho l$ & $E / G$ & $\begin{array}{c}v \\
\text { Passion } \\
\text { Ratio }\end{array}$ & $\begin{array}{c}L / R \\
\text { (length-to- } \\
\text { radius of } \\
\text { gyration) }\end{array}$ & $\begin{array}{c}\sqrt{\alpha}=\sqrt{\frac{\rho A L^{2}}{E I}} \\
\text { Non-dim } \\
\text { rotational speed }\end{array}$ \\
\hline 1 & 1 & 1 & 2.6 & 0.3 & 10 & 6 \\
\hline
\end{tabular}

\subsection{Periodic Rotating Timoshenko Beam}

For the sake of comparison, reference [8] is utilized where periodic rotating Euler Bernoulli beam had been analysed both numerically and experimentally. The parameters of the selected beam can be found in Table 3. Figure 4 shows the tip response of the selected beam in comparison with a similar plain beam of thickness $1 \mathrm{~mm}$ subjected to rotation speed or 5 revolutions per second $(300 \mathrm{rpm})$. It is clear from the figure that tip response is attenuated when average attenuation factor is nonzero. The current model showed good agreement with data published in reference [8].

Table 3: Characteristics of periodic rotating beam

\begin{tabular}{|c|c|c|c|c|c|c|c|c|c|c|}
\hline \multicolumn{3}{|c|}{$\begin{array}{c}\text { Material } \\
\text { (Aluminum) }\end{array}$} & \multicolumn{4}{c|}{ Beam dim. (cm) } & \multicolumn{2}{c|}{ Thin part } & \multicolumn{2}{c|}{ Thick Part } \\
\hline $\begin{array}{c}E \\
\mathrm{GPa}\end{array}$ & $v$ & $\begin{array}{c}\rho \\
\mathrm{Kg} / \mathrm{m}^{3}\end{array}$ & $\begin{array}{c}\text { Hub } \\
\text { radius }\end{array}$ & Length & width & $\begin{array}{c}\text { Cell } \\
\text { Length }\end{array}$ & $\begin{array}{c}\text { Length } \\
\mathrm{cm}\end{array}$ & $\begin{array}{c}\text { Thickness } \\
\mathrm{mm}\end{array}$ & $\begin{array}{c}\text { Length } \\
\mathrm{cm}\end{array}$ & $\begin{array}{c}\text { Thickness } \\
\mathrm{mm}\end{array}$ \\
\hline 71 & 0.3 & 2700 & 5 & 45 & 3.6 & 11.25 & 6.25 & 1 & 5 & 3 \\
\hline
\end{tabular}


Figure 5 shows the same beam when it is subjected to rotation speed of 3000rpm. From the figure it is noticed the attenuation factor is getting wider with less attenuation value.

\section{CONCLUSIONS}

In this study, a finite element model for a periodic rotating Timoshenko beam has been presented. From the results shown, the model proved that geometrical periodicity has high ability to attenuate vibrations in some frequency bands showing good agreement with published data. Also, increasing the rotation speed broaden the stop bands with less attenuation value. Proper design can achieve high attenuation value for some target frequency bands. Also, the selected 3-node 4 DOF/node element showed good results.

\section{REFERENCES}

[1] Mead D., "Wave propagation in continuous period structures: research contributions from Southampton, 1964-1995" Journal of Sound and Vibration 190, 495-524 (1996).

[2] Mead D. and Yaman Y., "The response of infinite periodic beams to point harmonic force: A flexural wave analysis", Journal of Sound and Vibration 144, 507-530 (1991).

[3] Mead D., White R. G. and Zhang X. M., "Power transmission in periodically supported infinite beam excited at a single point", Journal of Sound and Vibrations 169, 558-561 (1994).

[4] Ouyang H., Williams F. W. and Kennedy D., "Letters to the editor: A general method for analyzing wave propagation along longitudinally periodic structures", Journal of Sound and Vibration 177, 277-281 (1994).

[5] Langley R. S., "On the forced response of one-dimensional periodic structures: Vibration localization by damping", Journal of Sound and Vibration 178, 411-428 (1994).

[6] Lust S. D., Friedmann P. P., and Bendiksen O. O., "Free and forced response of multi-span beams and multi-bay trusses with localized modes", Journal of Sound and Vibration 180, 313-332 (1995).

[7] Heckl M. A., "Coupled waves on a periodically supported Timoshenko beam", Journal of Sound and Vibration 252, 849-882 (2002).

[8] Tawfik M., Chung J. and Baz A., "Wave Attenuation in Periodic Helicopter Blade", proceedings of the Fifth Jordan International Mechanical Engineering Conference, 26-28 April 2004, Amman, Jordan.

[9] Alaa El-Din M. and Tawfik M. "Vibration characteristics of rotating beams with periodically distributed piezoelectric dampers", Proceedings of the Thirteenth International Congress on Sound and Vibration (ICSV13), 2-6 July 2006, Vienna, Austria.

[10] Stafford R. D. and Giurgiutiu V., "Semi-analytical methods for rotating Timoshenko beams", International Journal of Mechanical Engineering 17, 719272 (1975). 
[11] Udupa K. M., and Varadan T. K., "Hierarchical finite element method for rotating beams", Journal of Sound and Vibration 138, 447-456 (1990).

[12] Mulmule S., Singh G. and Venkateswara Rao G., " Flexural vibration of rotating tapered Timoshenko beams", Journal of Sound and Vibration 160, 372-377 (1993).

[13] Lee S. Y. and Kuo Y. H., "Bending frequency of a rotating Timoshenko beam with general elastically restrained root", Journal of Sound and Vibration 162, 243-250 (1993).

[14] Du H., Lim M. K. and Liew K. M., " A power series solution for vibration of a rotating Timoshenko beam", Journal of Sound and Vibration 175, 505-523 (1994).

[15] Yoo H. H., Ryan R. R., and Scott R. A., "Dynamics of flexible beams undergoing overall motions", Journal of Sound and Vibration 181, $261-278$ (1995).

[16] Nagaraj V. T., "Approximate formula for the frequencies of a rotating Timoshenko beam", Journal of Aircraft 33, 637-639 (1996).

[17] Yoo H. H. and Shin S. H., "Vibration analysis of rotating cantilever beams", Journal of Sound and Vibration 212, 807-828 (1998).

[18] Hashemi S. M. and Richard M. J., "A new dynamic finite element (DFE) formulation for lateral free vibrations of Euler-Bernoulli spinning beams using trigonometric shape functions", Journal of Sound and Vibration 220, 601-624 (1999).

[19] Banerjee J. R., "Free vibration of centrifugally stiffened uniform and tapered beams using the dynamic stiffness method", Journal of Sound and Vibration 233, 857-875 (2000).

[20] Lin S. C. and Hsiao K. M., "Vibration analysis of a rotating Timoshenko beam", Journal of Sound and Vibration 240, 303-322 (2001).

[21] Rao S. and Gupta R., "Finite element vibration analysis of rotating Timoshenko beams", Journal of Sound and Vibration 242, 103-124 (2001).

[22] Chung J. and Yoo H. H., "Dynamic analysis of a rotating cantilever beam by using the finite element method", Journal of Sound and Vibration 249, 147-164 (2002).

[23] Yardimoglu B. and Yildirim Y., "Finite element model for vibration analysis of pre-twisted Timoshenko beam", Journal of Sound and Vibrations 273, 741-754 (2004). 


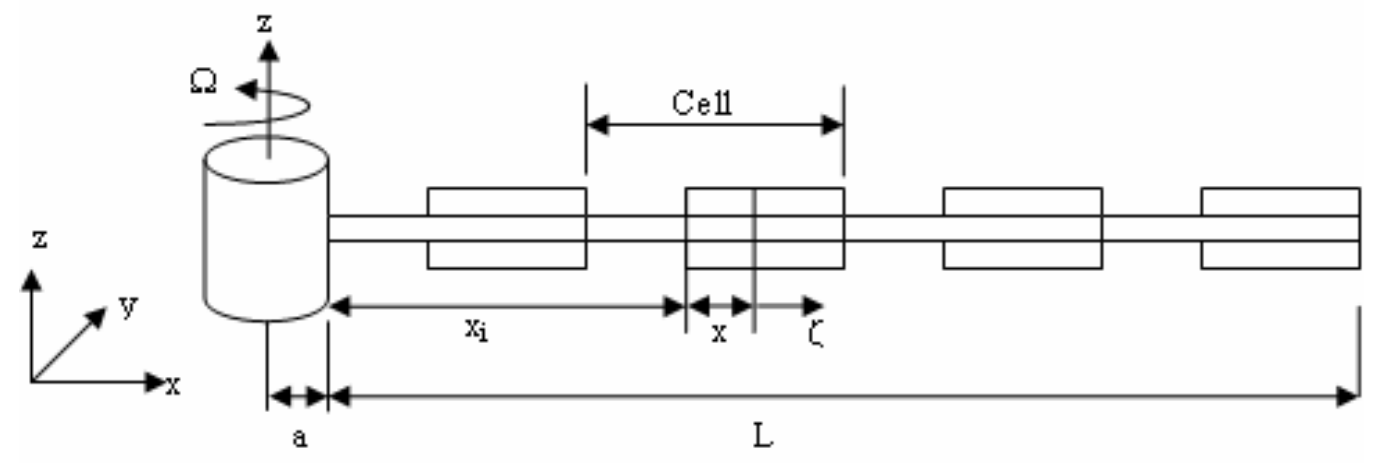

Figure 1: configuration of periodic rotating Timoshenko beam

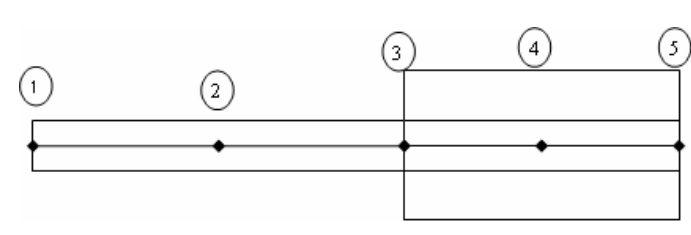

Figure 2: Typical cell configuration

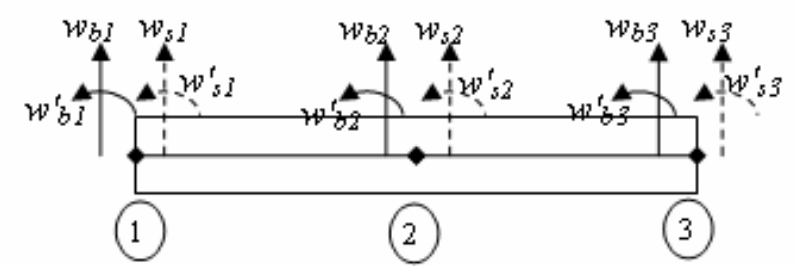

Figure 3: Element degrees of freedom

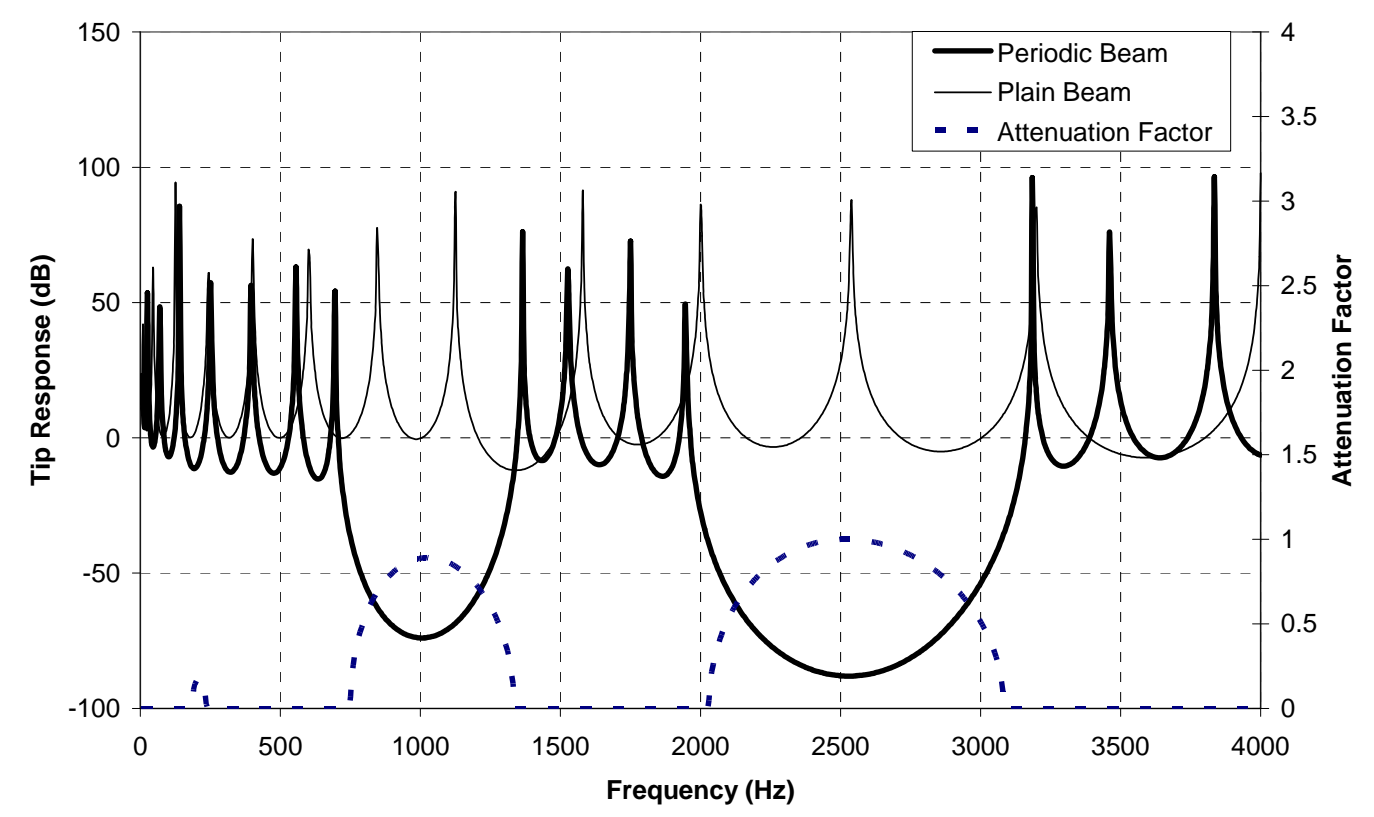

Figure 4: Frequency response of periodic rotating Timoshenko beam (5 rev/sec) 


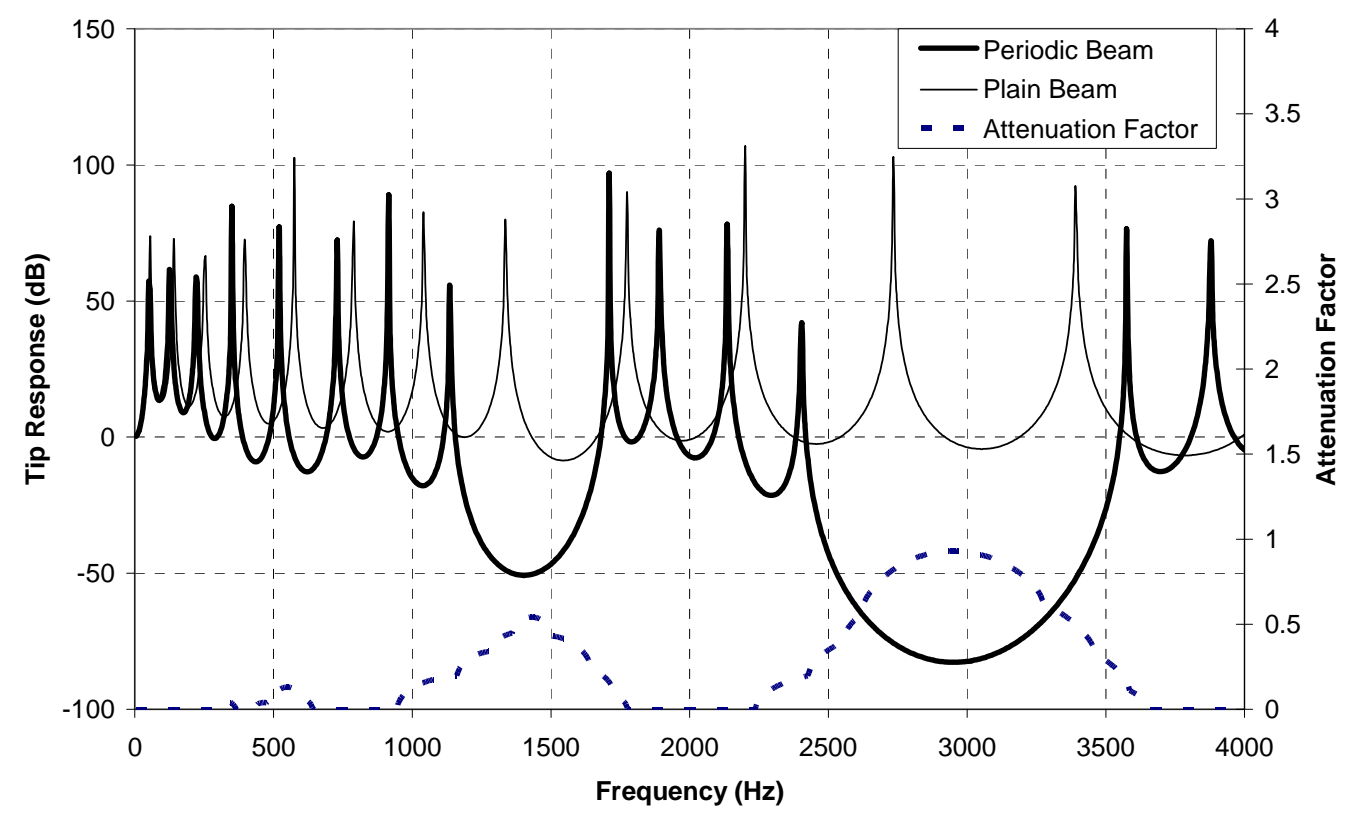

Figure 5: Frequency response of periodic rotating Timoshenko beam (50 rev/sec) 